\title{
FUTEBOL: POR UMA HISTÓRIA POLÍTICA DA PAIXÃO NACIONAL
}

\author{
Football: for a political history of the national passion \\ Luiz Carlos Ribeiro*
}

\begin{abstract}
RESUMO
A partir de uma leitura cultural e política do futebol, o artigo objetiva debater duas questões. A primeira é examinar como se estabeleceu historicamente, no Brasil, o campo de estudo do futebol e como esse conhecimento reproduziu o conceito de futebol como uma "paixão nacional". Para isso, o presente texto aborda o tema tanto sob o aspecto político e social quanto epistemológico. A segunda tem um caráter mais ensaístico e aborda algumas estratégias de como tratar histórica e politicamente a paixão brasileira pelo futebol. A partir do projeto de uma "História Social das Emoções Políticas", sugerida por autores da História Política, a proposta é historiar os sistemas sensíveis e questionar de que modo essas manifestações afetivas participam na sustentação do sistema futebolístico.
\end{abstract}

Palavras-chave: futebol; História Política; paixão; historiografia.

\begin{abstract}
From a cultural and political reading of football, the article aims to discuss two issues. The first is to examine how the field of soccer studies was historically settled in Brazil, and how this knowledge reproduced the concept of football as a "national passion". For this reason, this text approaches the subject considering the political, social and epistemological aspects. The second issue has an essayistic feature and discusses some strategies about how to treat historically and politically the Brazilian passion for football. From the project of a "Social History of Political Emotions", suggested by the authors of Political History, the proposal is historicizing the sensitive systems and question how these affective manifestations participate in sustaining the football system.
\end{abstract}

Key-words: football; Political History; passion; historiography. 


\section{Introdução}

A proposta do presente artigo é apresentar uma leitura política do futebol, problematizando-a no horizonte de uma história social das emoções políticas. ${ }^{1}$ Esta perspectiva vem me inquietando já há algum tempo. ${ }^{2} \mathrm{E}$ o ponto de inflexão desse incômodo têm sido as discussões sobre as possibilidades teóricas e metodológicas de constituição do campo de estudo do futebol, que venho tendo com os alunos da pós-graduação em História e no Núcleo de Estudos Futebol e Sociedade, da Universidade Federal do Paraná.

$O$ fato é que o futebol, muito antes de se tornar um tema de interesse das ciências sociais e políticas, era já um fenômeno de presença significativa na vida das pessoas. Antes que a academia constituísse a sua narrativa científica, o jornalismo esportivo e a produção não acadêmica dos memorialistas já haviam construído um vasto saber sobre tal esporte. A partir do momento em que os cientistas sociais passaram a tratá-lo como uma temática séria de pesquisa, várias disciplinas correram em sua direção. Isso fez com que o estudo do futebol se estabelecesse em um campo de fronteira disciplinar. Essa postura deu-se, também, porque este era um momento em que as ciências sociais encontravam-se inquietas em relação aos seus paradigmas. A História, em particular, inquiria sobre seus próprios métodos, fontes e teoremas explicadores de tal maneira que foi criticada por se dissolver em migalhas. ${ }^{3}$

Por conta desse processo, tanto nos congressos científicos quanto nas orientações de dissertações e teses, o diálogo interdisciplinar sobre o futebol tornou-se prática corrente. Uma plasticidade disciplinar que atuou tanto no sentido de fazer avançar a constituição do campo quanto no de intimidá-lo. No primeiro caso, atuou a Educação Física, que, por dever de ofício, há mais tempo vinha trabalhando uma história ou sociologia

1 ANSART, Pierre. Em defesa de uma Ciência Social das paixões políticas. História: Questões \& Debates. Curitiba: Ed. UFPR, ano 17, n. 33, jul.-dez. 2000, p. 145-162; ANSART, Pierre. La gestion des passions politiques. Lausanne (Suisse): Editions L'Age d'Homme, 1983; PROCHASSON, Christophe. Emoções e política: primeiras aproximações. Varia História. Belo Horizonte, v. 21, n. 34, p. 305-324, julho 2005.

2 RIBEIRO, Luiz Carlos. O futebol no campo afetivo da história. Movimento. Porto Alegre: UFRGS, v. 10, n. 3, p. 99-111, set./out. 2004.

3 DOSSE, François. A história em migalhas: dos "Annales" à Nova História. São Paulo: Ed. Unicamp, 1992. 
dos esportes. Porém, a carência teórica desta área contribuiu para que os estudos sobre o futebol surgissem carregados de uma visão descritiva, por simplificações marxistas produzidas a partir da chamada Teoria Crítica do Esporte $^{4}$ ou, ainda, por uma leitura carregada de empréstimos teóricos - em especial de Norbert Elias e Pierre Bourdieu -, por vezes pouco aprofundada e carente de distanciamento crítico. As saudáveis exceções confirmam a regra.

No segundo caso, encontramos a História, uma disciplina marcada por lugares consolidados de poder. Uma velha senhora ciosa de suas teorias, fontes, métodos e esquemas explicadores que, mesmo com o desmoronamento de seus paradigmas, resistiu - e ainda resiste - ao ingresso do novo sócio ao clube. As suas exigências são rigorosas: um campo de estudo consolidado, com corpo teórico, categorias e conceitos definidos, bem como uma historiografia consistente. Um jogo de poder que não é para principiantes.

Como na tradição científica da História - o estruturalismo dos Annales ou do marxismo - as operações historiográficas eram produzidas a partir de uma visão institucional de poder, a problematização dos modelos explicadores fez-se a partir desses lugares cristalizados. ${ }^{5} \mathrm{~A}$ alteridade, apesar de reconhecida e desejada, era o "outro", um estranho que precisava passar por um ritual científico de passagem para poder ser aceito como tema sério de pesquisa histórica. $\mathrm{O}$ "mundo do trabalho" talvez exemplifique melhor essa transição, nos estudos históricos, do institucional ou estabelecido Estado, classes sociais, consciência de classe, sindicato, partido - para o cultural, informal ou cotidiano - bares, botequim, mendicância, rua, igreja, costumes comuns como experiência. ${ }^{6}$ Neste caso, verificou-se um esforço mais compreensivo do que explicativo dos fenômenos históricos, procurando se despojar das visões funcionalistas e essencialistas que se tinha da cultura comum dos indivíduos e dos grupos sociais.

Então, por que o futebol ainda sofre resistência no campo da História? Sinceramente, temos apenas algumas especulações a este respeito. Talvez, a leitura de outro tema que adquiriu status acadêmico na virada epistemológica dos anos 70/80 nos auxilie. Assim como o futebol, a música

4 VAZ, Alexandre F. Teoria crítica do esporte: origens, polêmicas, atualidade. Esporte e Sociedade, Rio de Janeiro, v. 1, n. 1, p. 1-23, 2005.

5 CERTEAU, M. de. A escrita da história. Rio de Janeiro: Forense, 1982.

6 THOMPSON, E. P. Costumes em comum. Estudos sobre a cultura popular tradicional. São Paulo: Companhia das Letras, 1998. 
popular brasileira era, até então, assunto debatido apenas por memorialistas e pela crítica em jornais. Do mesmo modo como aconteceu com o futebol, também as investigações sobre a música popular precisaram construir seu campo de estudo e se inscrever no campo acadêmico. ${ }^{7}$

E o ponto de inflexão encontrado para essa elaboração teórica foi o da identidade nacional: "Na MPB é fundamental a problemática da nacionalidade", afirma Martha Ulhôa. ${ }^{8}$ Enfim, asseverar a música popular significava pensá-la como meio de "elevar o nível musical popular" e de "problematizar a nação". ${ }^{9}$ Assim como Antonio Cândido fizera com a construção do campo de estudo da literatura, no final dos anos 1950, também os estudiosos da música popular passaram a pensá-la como um "sistema" cultural:

No caso da música popular, os anos 60 consolidaram um verdadeiro "sistema" musical-popular, articulando "autor-obra-público-crítica" e instaurando uma nova maneira de pensar e viver a música popular em nosso país. ${ }^{10}$

Foi a partir desse conceito de envolvimento com o nacional que os historiadores da música popular brasileira elaboraram as primeiras categorias de análise, como define Napolitano: "jovem, universitário, de esquerda", sob a "vigência de uma cultura nacional-popular de esquerda" e que definia a MPB a partir de um "conceito de engajamento de esquerda". ${ }^{11}$ A música popular brasileira adquire, a partir de agora, a dignidade de tema de estudo e se institui como categoria histórica: a MPB.

Desse modo, a estratégia da música popular brasileira para se constituir em um campo de estudo aceito no meio acadêmico - em especial entre os historiadores - foi a de higienizar-se ideologicamente, trazendo

7 NAPOLITANO, Marcos. O conceito de MPB nos anos 60. História: Questões \& Debates, ano 16 , n. 31, p. 11-30, 1999.

8 ULHÔA, Martha T. de. Pertinência e música popular. Em busca de categorias para análise da música brasileira popular. In: Actas del III Congreso Latinoamericano de la Asociación Internacional para el Estudio de la Música Popular (23 y el 27 de agosto de 2000), p. 4. Disponível em: <www.hist.puc. $\mathrm{cl} /$ historia/iaspmla.html>. Acesso em: 10.09.2006.

9 NAPOLITANO, Marcos. A arte engajada e seus públicos (1955/168). Estudos Históricos, Rio de Janeiro, n. 28, p. 16, 2001.

10 Ibidem, p. 1.

11 Idem. 
para o seu baú epistemológico apenas categorias de agrado da academia, tais como "qualidade musical", "nacional-popular" e "engajamento". Todo o resto da produção musical do período, como, por exemplo, o fenômeno popular Roberto Carlos, foi negligenciado e permanece marginal. Assim como os artistas engajados dos anos 60/70, a inteligência acadêmica tem dificuldade em trabalhar com a indústria cultural de massa.

No futebol não foi possível tal processo de higienização, pois não havia no seu interior manifestações de "consciência nacional-popular" ou mesmo de "engajamento" de esquerda. Logo, assim como Roberto Carlos ou as novelas da Rede Globo de Televisão, ${ }^{12}$ o futebol não interessou aos historiadores e permaneceu como tema menor ou sem interesse.

Nessa direção, a disciplina que revelou maior disposição de abertura foi a Antropologia, que se esforçou em equilibrar a abertura a novos objetos com o rigor científico. A amplitude dada ao conceito de cultura contribuiu para isso, possibilitando aos antropólogos pautar seus métodos e corpos teóricos entranhados na prática, "embutidos nas experiências concretas" da pesquisa de campo, fazendo dela uma disciplina imersa na cultura comum dos povos. ${ }^{13}$

No Brasil, enquanto a Sociologia e a Ciência Política (incluindo a História) se encontravam engajadas na interpretação e legitimação do Estado-nação, o campo da crítica cultural estava aberto ao antropólogo, permitindo-lhe uma experimentação teórica e metodológica mais radical, como comenta Cornélia Eckert:

Em grande medida a qualidade da nossa Antropologia se reflete não só na diversidade de temas, mas também no fato de a produção acadêmica, em grande parte, não se radicalizar em um método, ou em uma teoria antropológica, experimentando ins-

12 Sobre o interesse da pesquisa acadêmica com a televisão, o historiador francês, Pierre Sorlin, comenta: "O cinema [...] finalmente teve reconhecida, depois de um século de desconfiança, sua dignidade de fonte íntegra. A televisão, em compensação, permanece largamente ignorada. Muito raros são os pesquisadores que se interessam pela instituição televisual, pelos conflitos de poder que ela provoca, pelo posto que ela ocupa no âmbito da informação." SORLIN, Pierre. Televisão: outra inteligência do passado. In: NÓVOA, J.; FRESSATO, S.; FEIGELSON, K. (Orgs.). Cinematógrafo: um olhar sobre a História. Salvador: EDUFBA; São Paulo: Ed. UNESP, 2009. p. 41.

13 DUARTE, Luiz F. D. O campo atual da Antropologia no Brasil. In: MARTINS, Carlos B.; DUARTE, Luiz F. D (Coords.). Horizontes das ciências sociais no Brasil: Antropologia. São Paulo: ANPOCS, 2010. p. 14. 
trumentos metodológicos e teorias sob uma ótica interdisciplinar mais ou menos eficaz para o estudo de problemas brasileiros. ${ }^{14}$

A perspectiva da Antropologia foi, nesse sentido, pensar os problemas brasileiros a partir da cultura popular, indígena, rural ou urbana. Foi o que lhe permitiu o devaneio ao marginal, dirigindo-se a temas secundários e não sérios de acordo com a tradição da ciência política, tais como a malandragem, o carnaval, a festa, os novos movimentos sociais e o futebol. Em síntese, embrenhou-se na compreensão do caráter - ou a falta de caráter - da nossa cordialidade. ${ }^{15}$

Em artigo recente, ao apresentar um balanço de vinte anos de estudos latino-americanos sobre esportes nas ciências sociais, o sociólogo argentino Pablo Alabarces afirma não terem mais sentido as "introduções queixosas" de que "pouco ou nada se estudou sobre o tema em nosso continente". ${ }^{16}$ Alabarces se refere aos comentários, comuns nos anos 1980/90, quando os pesquisadores do futebol sentiam-se outsiders, ou cientistas menores, por tratarem de um assunto considerado pelo meio acadêmico como política e socialmente irrelevante.

Essas considerações reproduziam as críticas feitas por Bourdieu, em 1983, quando afirmava que o estudo dos esportes era desdenhado tanto pelos sociólogos quanto pelos próprios esportistas. ${ }^{17}$ Mais enfático do que Bourdieu foi Eric Dunning no prefácio de A busca da excitação, de 1985, escrito em coautoria com Norbert Elias, quando se refere ao "desprezo da sociologia" para com os esportes. Para Dunning, a Sociologia teria se orientado exclusivamente para o "campo restrito dos aspectos 'sério' e 'racional' da vida", no que resultou que o "divertimento, o prazer, o jogo, as emoções e as tendências 'irracionais' e 'inconscientes' do homem e da mulher tivessem merecido escassa atenção" na teoria sociológica. ${ }^{18}$

1994.

14 ECKERT, Cornélia. Antropologia na atualidade. Anos 90, Porto Alegre, n. 2, p. 25, maio

15 DAMATTA, Roberto. Carnavais, malandros e heróis: para uma sociologia do dilema brasileiro. Rio de Janeiro: Zahar, 1979.

16 ALABARCES, Pablo. Vinte anos de ciências sociais e esportes, dez anos depois. Antropolítica, Niterói, n. 31, p. 17-30, $2^{\circ}$ semestre 2011. p. 19.

17 BOURDIEU, Pierre. Programa para uma sociologia do esporte. In: Coisas ditas. São Paulo: Brasiliense, 1990. p. 207.

18 ELIAS, Norbert; DUNNING. Eric. A busca da excitação. Lisboa: DIFEL, 1992. p. 16. 
Mas é inegável que, desde então, muito se produziu sobre o futebol. O tema é hoje discutido em congressos e publicações, vários grupos de pesquisa vêm sendo criados a partir de programas de pós-graduação, em diversas áreas do conhecimento. ${ }^{19}$ Porém, a respeito dessa consolidação do campo de estudo do futebol, afirmada por Alabarces, sou discordante em, pelo menos, dois aspectos. Um deles é o fato de o referido esporte, apesar de presente, ainda permanecer, enquanto tema, periférico nas Ciências Sociais - em especial na História, onde a resistência é forte, apesar de dissimulada. Sobre o segundo aspecto - de algum modo relacionado ao primeiro -, o próprio Alabarces dá a pista, ao falar de certa "saturação" dos estudos sobre o futebol. Tem havido, de fato, um crescimento numérico de trabalhos sobre futebol, mas essa percepção de saturação pode indicar a necessidade de problematizar as bases teóricas do campo. Apesar de festejados como um novo tema nas Ciências Sociais, em especial pela rica pesquisa empírica que proporcionou, os estudos do futebol necessitam projetar-se a voos mais arriscados na sua problematização teórica.

Como observamos, quase todos os pesquisadores que começaram a estudar o futebol vieram de campos acadêmicos consolidados. Nos anos oitenta, quando os estudos sobre o futebol tornaram-se mais sistemáticos, a base teórica das pesquisas tinha como referência os aspectos cognitivos da política, pressupondo sujeitos plenamente conscientes e racionais.

Como em qualquer campo de estudo, é preciso que as pesquisas do futebol continuem problematizando suas bases teóricas, seus métodos e se abram para outros documentos e novos problemas. Por exemplo, ainda é forte a tendência em restringir a análise política do esporte à sua relação com o Estado-nação ou a regimes de exceção. Apesar de não explicitado, a leitura do "político" no futebol parece manifestar-se apenas como manipulação, desvio de suas verdadeiras funções de esportividade e lazer, postos em prática por regimes autoritários ou em situações de convulsão social. As referências são os períodos autoritários na América do Sul (as ditaduras dos anos 1930/40 ou dos anos 1970) e na Europa (os regimes nazifascistas) ou

19 ALABARCES, op. cit. GIGLIO, Sérgio Settani; SPAGGIARI, Enrico. A produção das ciências humanas sobre futebol no Brasil: um panorama (1990-2009). Revista de História, São Paulo, n. 163, p. 293-350, jul./dez. 2010. GUEDES, Simoni L. Malandros, caxias e estrangeiros no futebol: de heróis a anti-heróis. In: GOMES, Laura G.; BARBOSA, Lívia; DRUMMOND, José A. O Brasil não é para principiantes: carnavais, malandros e heróis, 20 anos depois. Rio de Janeiro: FGV, 2000. p. 125-142. 
por ocasião dos grandes eventos esportivos, como a Copa do Mundo e os Jogos Olímpicos. Uma visão que atribui ao futebol a função social de lazer, associada à de tempo livre como tempo de ócio, de não trabalho, enfim, um não-lugar da política. Por essa concepção, o político no futebol só se manifesta na manipulação, como alienação. De todo modo, aos poucos os estudos do campo vêm alargando o conceito de política, bem como problematizando a dicotomia simplista e funcionalista entre política e lazer-esportividade.

\section{Sobre a formação do campo de estudo}

Meu interesse em retomar essa discussão não é no sentido de fazer queixas à resistência das Ciências Sociais aos estudos do futebol, mas procurar refletir sobre algumas das condições históricas e pressupostos teóricos que embasaram a formação do campo de estudo. E, nesse sentido, sugerir novos problemas ao estudo do futebol e do político, como o de pensá-los a partir não apenas da objetividade e da razão, mas também da subjetividade das emoções e dos sentimentos.

Apesar dos escritos sociais e políticos sobre o futebol serem de longa data, é consensual que a partir do final dos anos 1970 e, sobretudo, nos anos 1980, o estudo do futebol inicia sua formatação como um campo efetivo de crítica científica. Ou seja, é a partir desse momento que o meio acadêmico identifica, de maneira enfática, o futebol como objeto de estudos e propõe uma agenda de questões para a sua abordagem. É quando os estudos deixam de ser isolados ou efêmeros e passam a fazer parte sistêmica das ciências sociais e políticas. O objeto é definido, as balizas cronológicas são construídas, a historiografia tradicional e amadora (em geral de memorialistas) é trazida para a crítica científica, referências teóricas são arroladas no sentido de auxiliar no distanciamento crítico, documentos são recolhidos e analisados. Enfim, é quando o futebol começa a perder a invisibilidade científica.

Assim como ocorreu com outros temas - como o feminismo, o movimento negro ou dos homossexuais -, é também necessário pensar a formação do campo de estudo do futebol a partir tanto de fundamentos teóricos quanto de aspectos históricos e políticos. 
Ao analisar o processo de "descentramento" do indivíduo moderno na chamada pós-modernidade, Stuart Hall elenca "cinco grandes avanços na teoria social e nas ciências humanas", ocorridos no pensamento ocidental. ${ }^{20}$ Entre outros, cita como um desses descentramentos da teoria social o impacto do feminismo no pensamento contemporâneo, "tanto como uma crítica teórica", constituindo portanto o feminismo como um campo de estudo, "quanto como um movimento social", inserindo-o no movimento mais amplo das revoluções terceiro-mundistas, nos movimentos pela paz e tudo que estava associado a "1968". ${ }^{21}$

É com essa estratégia de leitura do feminismo, sugerida por Hall, que proponho entender o momento de formação do campo de estudo do futebol. É óbvio que este não tem a mesma dimensão do feminismo, mas o que me interessa é o método de abordagem: analisar a formação do campo de estudo do futebol como constituinte tanto dos movimentos sociais, econômicos e políticos quanto das rupturas epistêmicas.

Em outras palavras, devemos perguntar por que e em que condições o futebol passou a se constituir, nos anos oitenta, enquanto tema de interesse das Ciências Sociais, tanto na Europa (Inglaterra, França, Espanha, Alemanha e Itália) como na América Latina (Brasil e Argentina) - não por acaso regiões onde o futebol é mais praticado. Dada a complexidade, o que proponho é o mapeamento de algumas dessas condições históricas e da crítica teórica que teriam favorecido a construção do campo.

A primeira inflexão ou, se quisermos abusar da nomenclatura proposta por Hall, o primeiro descentramento, refere-se às mudanças econômicas, políticas e sociais vivenciadas no Brasil e no mundo, no final dos anos 1970 e início dos 80. No Brasil, processos como o esgotamento da ditadura civil-militar, a redemocratização e a explosão de novos movimentos sociais nos auxiliam nessa reflexão. No plano internacional, a crise do boom econômico e do welfare state, vigentes desde o pós-II Guerra, culminando com o fim da guerra fria, o desmonte do bloco soviético e dos ideais socialistas e revolucionários.

Em nosso país, a emergência dos novos movimentos sociais marcou a luta pela redemocratização. Os movimentos (trabalhistas, luta pela mora2005 .

20 HALL, Stuart. A identidade cultural na pós-modernidade. 10. ed. Rio de Janeiro: DO\&A,

21 HALL, 2005, op. cit., p. 44. 
dia, emprego, direitos das mulheres, negros, entre outros) liderados pelos sindicatos, igreja ou partidos políticos, eram heterogêneos e não tinham mais como referência as cartas ideológicas revolucionárias do passado, mas sim a disputa do poder local e particular dos grupos de interesse, como analisa Marco Aurélio Garcia:

Esses chamados "novos movimentos sociais" correspondem à (re)descoberta e/ou (re)valorização de temas ausentes ou minimizados pelo pensamento das esquerdas tradicionais ou, o que é mais importante, a uma nova reflexão substantiva sobre a democracia, entendida como espaço de criação de novos direitos. [...] A democracia política não apenas, como no passado, como um meio - etapa ou instrumento - mas como um fim, um objetivo a ser construído. ${ }^{22}$

Foi uma reconstrução democrática que ocorreu num contexto tanto de crise econômica (final de 1970 e anos 80) como de retomada do crescimento e de nova mundialização do mercado, a partir dos anos 90. É quando se impõe uma cultura política de maior inserção na economia internacional, minimizando-se, por consequência, a importância das questões nacionais no desenvolvimento do país.

Ocorre, desse modo, um fenômeno de desinteresse político e cultural pela questão nacional, motivado por um duplo impulso: de um lado, o crescimento de movimentos sociais pautados em interesses específicos e, ao mesmo tempo, críticos à herança autoritária do Estado; de outro, a transferência de poderes do Estado nacional para a lógica do mercado internacional. Com isso, esgotam-se as necessidades e expectativas - presentes há mais de um século no cenário intelectual e político brasileiro - de se reinventar o nacional e o nacionalismo.

Essa tendência repercute no meio científico, pois a academia experimentava, desde os anos 1970 e 80, a expansão das universidades e a emergência de um sistema nacional de pós-graduação, o que resultou

22 GARCIA, Marco Aurélio. Esquerdas: rupturas e continuidades. In: DAGNINO, Evelina (Org.). Os anos 90: política e sociedade no Brasil. São Paulo: Brasiliense, 1994. p. 124-125. Grifos no original. 
num processo de institucionalização das Ciências Sociais, como observa Renato Ortiz. ${ }^{23}$

A pesquisa social e política desenvolvida nas universidades, apesar de instituída numa estrutura de modernização autoritária, experimenta agora, com a redemocratização e a emergência de novos movimentos sociais, uma significativa oxigenação intelectual.

Significa dizer que temas tradicionais dos estudos políticos, como as interpretações do Estado-nação ou da revolução - geralmente correlatos -, gradativamente perdem relevância nas Ciências Sociais. Desengajada da totalidade nacional, a "nova" ciência política volta-se para a diversidade das experiências particulares, distanciando-se da hegemonia política e se aproximando dos estudos culturais. Constata-se, assim, "o deslocamento do debate, da identidade nacional para as identidades particulares (étnicas, de gênero e regionais)", assim como se passa a reconhecer essas instâncias como lugar de poder. ${ }^{24} \mathrm{Ou}$, como afirma Ortiz, "conceber a esfera da cultura como um lugar de poder significa dizer que a produção e a reprodução da sociedade passam necessariamente por sua compreensão". ${ }^{25}$

Foi, portanto, esse contexto de abertura política e de mundialização que permitiu à inteligência brasileira atualizar a crítica teórica, em relação ao resto do mundo.

Foram decisivas as edições em língua portuguesa, a partir do final dos anos 70, de autores como E. P. Thompson, Raymond Willians, Eric Hobsbawm, Cornelius Castoriadis. Do mesmo modo, Michel Foucault e Pierre Bourdieu têm seus livros traduzidos quase de forma simultânea no Brasil. Os escritos de Walter Benjamin ou de Norbert Elias, revalorizados no ocidente europeu nos anos 70, são concomitantemente publicados no Brasil.

Uma avalanche editorial, que estimulou na ciência política local a crítica aos paradigmas explicadores e a discussão em torno da tríade obscura e complexa do pós-estruturalismo, do pós-modernismo e da globalização. ${ }^{26}$ Um debate que excitou a discussão tanto da crise dos valores universais da razão iluminista quanto da nossa busca incessante pela modernidade.

23 ORTIZ, Renato. As ciências sociais e a cultura. Tempo Social, Rev. Sociol. USP, S. Paulo, v. 14, n. 1, p. 19-32, maio de 2002. p. 26.

24 Idem.

25 Ibidem, p. 29.

26 FEATHERSTONE, Mike. A globalização da complexidade. Pós-modernismo e cultura do consumo. Revista Brasileira de Ciências Sociais, n. 32, 1996. 
De forma pouco clara, passamos a compartilhar um sentimento de vazio civilizacional. A sensação era de que nação, estado e, sobretudo, o indivíduo moderno, haviam sido evaporados ou liquefeitos.

O tratamento em geral dado a esse novo mal-estar civilizacional era o de que os impactos da reestruturação produtiva, a liberação dos mercados, bem como a redefinição do papel do estado dos últimos trinta/quarenta anos teriam esgotado a solidez democrática e republicana da sociedade moderna, produzindo, em contrapartida, "sociedades flexíveis, sem fronteiras e sem limites, sociedades fluidas, sociedades líquidas". ${ }^{27}$ Uma sociedade produtora de uma individualidade hipermoderna e negativa, oposta àquela engajada e solidária do indivíduo republicano. ${ }^{28}$

Para Renato Ortiz, a globalização e a crise da modernidade (ou o pós-modernismo) teriam encontrado, na incompleta modernidade brasileira, um solo fértil onde se enraizar. Para o sociólogo, as incertezas da pós-modernidade foram apreendidas sem grandes problemas pela política e pela reflexão intelectual nacional, pois a defasagem temporal que existia aqui, em relação ao moderno, tornara-se inexpressiva:

A modernidade pressupunha uma temporalidade progressiva na qual a América Latina só encontraria lugar num momento futuro; a globalização [e o pós-modernismo] implica a ideia de uma compressão do tempo, as diferentes partes do planeta são atravessadas pelo seu fluxo. ${ }^{29}$

Outro fator de descentramento, que nos ajuda a compreender a constituição do campo de estudo do futebol, foram as transformações estruturais que a modalidade experimentou, no Brasil e no mundo, a partir dos anos 1980. É fundamental reconhecer a sua transformação em um fenômeno da indústria cultural e de massa, bem como em paradigma explicador do mundo global e pós-moderno. ${ }^{30}$ Essa mudança nos ajuda a compreender

27 HAROCHE, Claudine. Maneiras de ser, maneiras de sentir do indivíduo hipermoderno. Ágora, v. VII, n. 2, p. 221-234, jul./dez. 2004.

28 CASTEL, Robert; HAROCHE, Claudine. Propriété privée, proprieté sociale, proprieté de soi. Paris: Hachettes, 2001.

29 ORTIZ, Renato. Globalização: notas sobre um debate. Sociedade e Estado, Brasília, v. 24, n. 1, p. 231-254, jan./abr. 2009. p. 234.

30 PRONI, Marcelo W. As metamorfoses do futebol. Campinas: Ed. Unicamp, 2000. DAMO, op. cit. 
como o futebol vivenciou seu ritual de iniciação como "um campo sério" no interior dos modelos explicadores tradicionais.

A expansão comercial do futebol e sua transformação em indústria cultural e de massa - inicialmente na Europa, nos anos 80 - deram-lhe visibilidade política e intelectual. O impacto econômico e social desse crescimento fez com que as autoridades públicas da União Europeia passassem a se preocupar com os destinos da atividade. Foi um crescimento pautado no desregramento do mercado global, trazendo consigo a desestruturação da educação esportiva (a perda do valor moral e educativo dos esportes). Crescimento associado, entre outros fatores, ao tráfico ilegal de atletas, lavagem de dinheiro e crescimento da violência entre as torcidas dos clubes. ${ }^{31}$

Desse modo, o estado europeu (Estados nacionais e União Europeia) iniciou um processo de desmonte da autonomia de que o sistema esportivo futebolístico gozava em relação ao poder público e ao direito comunitário. Uma intervenção sincrônica à compreensão intelectual do fenômeno, para o qual a participação da academia passou a ser reclamada. Segundo narra o historiador Bernardo B. B. de Hollanda, um exemplo desse envolvimento ocorreu com um grupo de sociólogos ingleses (ligados à orientação teórica de Norbert Elias) que, por solicitação do Social Science Research Council, desenvolveu entre 1979-1982 uma pesquisa sobre a violência no futebol inglês. Conclui, ainda, Hollanda:

O recrutamento de quadros universitários oriundos das Ciências Humanas e Sociais para a proposição de políticas preventivas se disseminaria por todo o continente, com apoio financeiro muitas vezes da União Europeia e da UEFA. ${ }^{32}$

Vários campos do conhecimento científico se mobilizaram, por interesses os mais diversos, em direção ao futebol: a Psicologia, interessada na convergência passional e na violência das multidões que se formaram em volta do esporte; a Comunicação, no fenômeno midiático; a Economia, no tamanho financeiro que o futebol obteve, na lavagem de dinheiro etc.;

31 RIBEIRO, Luiz Carlos (Org.). Futebol e globalização. Jundiaí: Fontoura, 2007.

32 HOLLANDA, Bernardo B. B. de; MELO, Victor A. de (Orgs.). O esporte na imprensa e a imprensa esportiva no Brasil. Rio de janeiro: 7Letras, 2012. p. 360. 
o Direito, na autonomia jurídica que o esporte gozava e a necessidade de enquadrá-lo no direito comum; a Sociologia e a Antropologia, nos impactos sociais urbanos (uma nova tribo?), no movimento migratório de atletas, entre muitas outras. O futebol deixa de ser um objeto invisível. O mundo passou a olhar para o futebol e a percebê-lo como um fenômeno social difuso, aparentemente sem caráter de classe ou com interesses políticos conhecidos. Uma atividade marginal, até então restrita a machos beberrões, mas que agora se inscrevia de forma significativa na sociedade global.

É nessa tessitura de deslocamentos intelectuais e políticos que surgem, no final dos anos 1970, os escritos acadêmicos sobre futebol no Brasil. Foi quando Roberto DaMatta, com análises tanto inaugurais quanto tardias, nos impressionou com a assertiva de que o futebol explica o Brasil. Inaugural, porque os seus escritos foram os primeiros com uma abordagem acadêmica. Tardia, porque a descrição que nos deu do futebol estava mais próxima dos anos 1940-60, de Gilberto Freyre e Mario Filho, do que da desgastada integridade nacional dos anos 80 . Futebol e nação estavam sendo ressignificados, perdiam coesão, logo, associá-los era mais um dos recorrentes exercícios de buscar no passado o sentido da nação que o presente corroía.

Um manifesto sentimento intelectual e político de perda de valores civilizacionais que estimulava, no pensamento brasileiro, o retorno ao lugar-comum das nossas raízes e a busca de nossos significados como povo e nação, no qual o futebol, enquanto uma cultura popular, parecia servir.

Uma situação paradoxal, mas que não era exclusiva de Roberto DaMatta. Desde o final dos 80 (e ainda hoje com resquícios), uma parcela significativa da intelligentsia nacional ressente o esgotamento das certezas intelectuais e ideológicas da ideia de revolução ou do Estado-nação. O dilema vivido é que a sonhada construção nacional parecia continuar marcada por uma "incompletude identitária", afundada na "ninguendade" de um povo impedido de sê-lo, como afirmou Darci Ribeiro na sua última obra, O povo brasileiro, de $1995 .{ }^{33}$

A impressão é de que as instabilidades identitárias dos anos 1980/90 reacenderam a (eterna) busca da nossa identidade. Atitude que levou a his-

33 Apud BRESCIANI, Stella. Identidades inconclusas no Brasil do século XX. Fundamentos de um lugar-comum. In: ___ _ _ NAXARA, Márcia (Orgs.). Memória e (res)sentimento. Indagações sobre uma questão sensivel. Campinas: Ed. Unicamp. 2001, p. 405. 
toriadora Maria Stella Bresciani a questionar: o que "até hoje justificaria essa busca persistente e aparentemente ininterrupta?". ${ }^{34}$

O obscurantismo intelectual imposto pela ditadura se depara, nos anos 80 e 90, com um ceticismo, tanto epistêmico quanto ideológico, em relação ao indivíduo e à ideia de nação. Circunstância que provocou uma contradição, pois estimulou setores da intelectualidade a resgatar a vontade da refundação nacional. Evidenciam essa tendência as atividades relativas aos 500 anos do descobrimento do Brasil, com a publicação de importantes coletâneas reeditando e comentando clássicos do pensamento brasileiro, tais como as coordenadas por Lourenço Dantas Mota, Um banquete no trópico ${ }^{35}$ e por Silviano Santiago, Intérpretes do Brasil ${ }^{36}$ o já citado livro de Darci Ribeiro, de 1995, O povo brasileiro; A formação e o sentido do Brasil, que foi adaptado em 2000 para o formato de vídeo, recebendo participações especiais de diversos intelectuais brasileiros e, sobretudo, de artistas, tais como Chico Buarque, Tom Zé, Gilberto Gil e Luiz Melodia um documentário de excelente qualidade fílmica e de forte apelo emocional às nossas raízes identitárias.

Outro exemplo expressivo de como as discussões sobre nossas raízes estão sendo reatualizadas são as palavras do então Presidente da República, Fernando Henrique Cardoso, pronunciadas no Instituto Histórico e Geográfico Brasileiro (IHGB), em 1999. Ele que, junto com Florestan Fernandes e outros pesquisadores da chamada escola de sociologia paulista, havia sido nos anos 60 um dos mais ferrenhos críticos de Freyre, apresenta agora um discurso conciliador com o desafeto, ao mesmo tempo em que se revela menos seguro do papel da luta de classes e da revolução, para a compreensão e o enfrentamento da questão racial no Brasil. Analisemos um extrato dessa revisão de conceitos:

Casa Grande e Senzala nos fez assumir com orgulho a condição de mestiço, vista não mais sob o prisma exclusivo da raça, mas pela ótica da cultura. [...] Mestiçagem significava aptidão em conjugar diferenças, em plasmar costumes e valores. Isto nos

34 Idem.

35 MOTA, Lourenço Dantas (Org.). Um banquete no trópico. São Paulo: Edit. SENAC, 1999. 2000.

36 SANTIAGO, Silviano (Coord.). Intérpretes do Brasil. 3 v. Rio de Janeiro: Nova Aguilar, 
teria credenciado a construir uma civilização híbrida, e por isso mesmo viável, nos trópicos. Igualmente plásticos haviam sido os portugueses, enaltecia Freyre, que não tinha dúvidas sobre o êxito da gesta colonizadora. [...]

Sim, saúdo Gilberto Freyre pelas intuições sobre nossa plasticidade cultural, a despeito do véu lançado sobre os conflitos de classe. É hora de admitir que o Brasil comporta Florestan e Freyre, que tanto o sentimento de um como o do outro são procedentes, que o país é, ao mesmo tempo, socialmente injusto e culturalmente integrador. Sem que aceitemos essas duas evidências, por mais antagônicas que possam parecer, não enfrentaremos o desafio de fazer com que a plástica que nos habilita a integrar o jazz ao samba, o rap ao maracatu, vingue também nas relações sociais, reduzindo distâncias, aproximando contrários. ${ }^{37}$

Esta manifestação, mais do que simbolizar a tentativa de resgate de Gilberto Freyre do ostracismo que a academia havia lhe imposto, enuncia as incertezas das ciências sociais e políticas diante do mundo global e pós-moderno, bem como do esvaziamento da ideia de nação.

É nesse contexto de busca de nossas identidades que os estudos do futebol vivenciam seu ritual de iniciação como "um campo sério" no interior das Ciências Sociais. A necessidade crônica do eterno retorno às nossas raízes e às nossas incompletudes - assim como fizeram Mario de Andrade com Macunaíma, Freyre com o mulato ou Sérgio Buarque de Holanda com a cordialidade do homem brasileiro - descobria o futebol como um lugar-comum identitário ainda não visitado.

Uma identidade vista agora como um retorno romântico à pureza popular que teria sido perdida com a ditadura, mas que não conseguia encontrar solidez ideológica num mundo marcado pela liquidez dos princípios republicanos. E, talvez, Roberto DaMatta tenha sido quem melhor interpretou esse "drama social" (como ele próprio denominou), através de duas obras seminais: Carnavais, malandros e heróis, de $1979,{ }^{38}$ e o artigo

37 CARDOSO, Fernando Henrique. Palestra do Senhor Presidente da República Fernando Henrique Cardoso no Instituto Histórico e Geográfico Brasileiro (IHGB). Rio de Janeiro, 3 de outubro de 1999. Disponível em: <http://www.mre.gov.br/sei/pr-ihgb.htm>. Acesso em: 23.03.2003.

38 DAMATTA, Roberto. Carnavais, malandros e heróis: para uma sociologia do dilema brasileiro. Rio de Janeiro: Zahar, 1979. 
"Esporte na sociedade: um ensaio sobre o futebol brasileiro", presente na coletânea por ele organizada em 1982. ${ }^{39}$

Criticando a visão, à época hegemônica nos estudos marxistas, do futebol como ópio do povo, alienante e incapaz de permitir uma leitura do social, DaMatta afirmará o seu projeto de leitura do futebol como expressão do que denominou de "dilema brasileiro":

Estudando o futebol e o esporte como drama, pretendo analisar essas atividades como modos privilegiados através dos quais a sociedade se deixa perceber ou "ler" por seus membros. [...] O futebol praticado, vivido, discutido e teorizado no Brasil seria um modo específico, entre tantos outros, pelo qual a sociedade brasileira fala, apresenta-se, revela-se, deixando-se portanto, descobrir. ${ }^{40}$

A sua referência foi também o desinteresse das ciências sociais ao futebol e a outras manifestações da cultura popular brasileira:

Juntamente com o Carnaval, o "Você sabe com quem está falando", o futebol e a música popular, não se constituem em "coisas sérias", dignas de um estudo sociológico, que deveria ser orientado para as chamadas "tarefas urgentes" ou "problemas politicamente relevantes". Saber o porquê desse preconceito contra o estudo do verdadeiramente familiar é um trabalho importante, que ainda deverá ser realizado. ${ }^{41}$

Simoni Guedes afirma ter sido essa leitura de DaMatta sobre a cultura brasileira que provocou o "crescente interesse de historiadores, sociólogos e antropólogos na análise do futebol brasileiro como fenômeno social" ${ }^{42}$

39 DAMATTA, Roberto. Esporte na sociedade: um ensaio sobre o futebol brasileiro. In: (Org.). Universo do futebol: esporte e sociedade brasileira. Rio de Janeiro: Pinakotheke, 1982. p.

40 DAMATTA, 1982, op. cit., p. 21.

41 DAMATTA, 1979, op. cit., p. 212.

42 GUEDES, op. cit., p. 127. 


\section{Problematizando o campo de estudo}

De fato, DaMatta nos construiu um ponto seguro para o início dos estudos do futebol. Mas, junto ao desenvolvimento dos estudos, foi se revelando como este se encontrava enclausurado no misticismo freyreano de nossas origens. Iniciou-se, então, uma respeitosa desconstrução da sua visão romântica do futebol. Tanto do ponto de vista crítico quanto político, as análises de DaMatta começaram a se tornar insuficientes. Os novos estudos ampliaram as fontes, introduziram novos corpos teóricos e problematizaram os objetos, tais como a análise da imprensa (o papel político e ideológico das mídias), em especial a crônica (a relação da Literatura com a História); o comportamento das torcidas, com o envolvimento participativo de antropólogos; a estrutura governativa dos clubes e federações; a força econômica do mercado, com destaque para a televisão e os patrocinadores, entre muitos outros.

DaMatta nos propôs superar "o sabor utilitarista-funcionalista"43 das Ciências Sociais e, pelo estudo do futebol, alcançarmos "a oportunidade clara e concreta de passar de um código ideológico para um código visual, auditivo, táctil, corporal e de odores". ${ }^{4}$

Parecia, então, que nos incitava a romper com o racionalismo das ciências sociais, bem como a mergulhar na subjetividade e na intersubjetividade dos indivíduos e das sociedades, mas acabou construindo estruturas imóveis, "sistematizando nossos autoenganos". ${ }^{45}$

A subjetividade sugerida para a interpretação social e histórica do futebol é excessivamente estruturada. A "paixão do brasileiro pelo futebol" é apresentada como uma subjetividade tornada essência, desprovida de tempo e experiência efetiva. Na intenção de problematizar a imobilidade dessa paixão, o desafio agora é historicizá-la.

Não se trata, por outro modo, de propor uma ciência social subjetivista, que reduza a complexidade social às intenções individuais autônomas

43 DAMATTA, op. cit., 1982, p. 22.

44 Ibidem, p. 14.

45 SOUZA, Jessé. A sociologia dual de Roberto da Matta: descobrindo nossos mistérios ou sistematizando nossos autoenganos? Revista Brasileira de Ciências Sociais, v. 16, n. 45, p. 47-67, fevereiro 2001 . 
dos agentes, mas sim de evitar que a "gramática social profunda" ${ }^{46}$ soterre as indeterminações dos agentes.

A paixão do brasileiro pelo futebol não pode ser analisada como uma coisa dada. Reiterada dessa forma, ela é vazia, autorreferida e não nos ajuda na compreensão do futebol. É preciso desconstruir esses axiomas a partir da experiência complexa dos indivíduos, dos grupos sociais e das instituições.

Pela força que adquiriu como lugar-comum que explica o Brasil, a assertiva não deixa de existir, mas perdeu significado. Repeti-la à exaustão, como ainda se faz no meio acadêmico e, sobretudo, na imprensa esportiva, apenas enreda a leitura do futebol no folclórico e na mitificação.

A alternativa é problematizar essa paixão enquanto uma experiência de vida, individual e social. Subjetiva, enfim. Interpretar a experiência histórica como a água corrente do rio: apesar da perenidade do rio, não se entra duas vezes na mesma água, logo, o rio é outro, como Foucault preferiu para explicar a subjetividade. ${ }^{47}$

A proposta de Pierre Ansart, ${ }^{48}$ de superar o racional-cientificismo das ciências sociais e evitar a armadilha dos determinismos psicológicos, pode nos auxiliar nessa tarefa. $\mathrm{O}$ argumento toma uma dimensão mais ampla quando Prochasson denomina este procedimento como uma "História Social das Emoções Políticas" e sugere "agregar as dimensões simbólicas e afetivas ao estudo da política". ${ }^{49}$

Do mesmo modo, os antropólogos Mariella Pandolfi e Vincent Crapanzano propõem um procedimento como uma "antropologia das emoções", na qual "o contágio das paixões", por mais "ilusório que possa parecer", deve ser estudado em um quadro sociopolítico em que se reconhece o papel das paixões e das emoções na fragilidade, na inconstância e na artificialidade, mesmo dos arranjos sociais e políticos..$^{50}$

46 DAMATTA, Roberto. A casa e a rua. Rio de Janeiro: Guanabara Koogan, 1991.

47 Apud CARDOSO JR, Hélio R. Para que serve uma subjetividade? Foucault, tempo e corpo. Psicologia: Reflexão e Crítica, Porto Alegre, v. 18, n. 3, p. 346, 2005.

48 ANSART, 2000, op. cit.

49 PROCHASSON, 2005, op. cit., p. 305.

50 PANDOLFI, Mariella; CRAPANZANO, Vincent. Présentation. Les passions: au coeur du politique? Anthropologie et Societétés, v. 32, n. 3, p. 9, 2008. 
Nesse sentido, qual o sentido social da "paixão do brasileiro pelo futebol"? Como historicamente podemos compreendê-la, sem cair na tentação dos a priori sobre a relação afetiva do torcedor brasileiro com o futebol?

Para enfrentar essa questão, desde o princípio é preciso reconhecer que o envolvimento do brasileiro com o futebol é uma experiência forte, independente das interpretações feitas por interesses os mais diversos. A existência de centenas de clubes, entre profissionais e amadores, a sua prática como lazer entre amigos, nos clubes sociais ou nos terrenos baldios, nos índices de audiência - antes no rádio, agora na televisão e outras mídias - são evidências do efetivo envolvimento do brasileiro com o esporte. Mas essas características são encontradas também em outras sociedades, como a britânica, italiana ou argentina. Portanto, ele é um fenômeno tanto local, brasileiro, como internacional, logo, cosmopolita. O problema, assim, é a simplificação que se produziu sobre o "gostar de futebol" como algo atávico ao povo brasileiro.

Diante do ressentimento à nossa incompletude civilizacional, a naturalização da paixão do brasileiro pelo futebol tornou-se um ardil compensatório. Uma produção de nossos intérpretes, que ao longo do tempo passou a ser reconhecida como a "nossa" identidade, entre as quais estariam também o samba ou o carnaval. Uma leitura da paixão futebolística como síntese da "dialética rarefeita entre o não-ser e o SER outro", como formulou Paulo Emílio Salles Gomes sobre nossa identidade cultural. ${ }^{51}$

Uma visão de mundo construída pela necessidade intelectual e política de imaginar a nação. Nosso questionamento se refere ao modo com que esse discurso, homogeneizador da identidade do Brasil, se apropriou desse sentimento. Uma afeição que se desenvolveu de forma autônoma pelos indivíduos comuns, sem que necessariamente existisse nela a consciência do nacional. Assim, o forte envolvimento de setores da população brasileira com o futebol ocorreu anterior e independentemente dos sintetizadores de nossa identidade. Não foi a vontade política de Vargas ou os textos da Mario Filho, Nelson Rodrigues ou Gilberto Freyre que produziram o envolvimento do brasileiro com o futebol. O que esses estrategistas fizeram foi ancorar seus projetos políticos de nação à emoção de torcer. Eles amarraram com maestria um projeto político às manifestações culturais, que se organiza-

51 GOMES, Paulo Emilio Salles. Cinema: trajetória no subdesenvolvimento. 2. ed. Rio de Janeiro: Paz e Terra, 2001. p. 90. 
vam de forma tensa e fluida no tecido social brasileiro. A eficácia desses intérpretes da nação foi a de estabelecer função social e sentido ao que era indeterminação, manifestação espontânea, identidade local e particular. $\mathrm{Ou}$ seja, reduziram a experiência polissêmica dos indivíduos - a paixão pelo futebol - a uma essência. Por esse raciocínio, conceitos como "construção", "formação" ou "sistema" são posteriores e externos às práticas cotidianas dos indivíduos, como, por exemplo, a de torcer por um clube de futebol.

$\mathrm{O}$ indivíduo comum, no seu cotidiano de ir à igreja, à padaria e ao estádio de futebol, torcer pelo seu clube ou para o selecionado nacional, não age pensando em construir uma unidade abstrata, a nação. Assim como seria ingenuidade imaginar que o envolvimento afetivo dos indivíduos com o futebol é natural, puro ou espontâneo, isento de uma rede de interesses. Logo, desnaturalizar não é ignorar o envolvimento passional do brasileiro com o futebol, mas historiar esse sentimento. Não será nos restringindo às explicações generalizantes que iremos desconstruir o teorema.

A cultura política do nacionalismo exerce sobre as vontades individuais uma força homogeneizadora, de modo a ocultar ou mesmo apagar essas vontades. Mas essa força, ao mesmo tempo em que pretende instituir "a alma do povo", também contém uma vontade "indignada e desesperada de reintroduzir a verticalidade [...] no espaço igualitário da cidadania democrática". ${ }^{52}$ De forma contraditória, o discurso nacionalista "repolitiza" questões que o liberalismo havia remetido à privacidade das consciências, tal como o racismo, por exemplo. Para Zawadzki, o nacionalismo

é desigualitário no sentido de que abandona a democracia em benefício da "etnocracia" e valoriza a "etnolatria" em detrimento do universalismo dos direitos do homem e da cidadania. [...] Ao contrato livremente escolhido por indivíduos autônomos, ele opõe o princípio holista do gênio, do Volksgeist, um caráter nacional, uma alma do povo. ${ }^{53}$

O desejo dos intérpretes é de que a "alma do povo" (o nacional) seja, em detrimento de outros discursos, sua imagem e semelhança. Todavia,

52 ZAWADZKI, Paul. O ressentimento e a igualdade: contribuição para uma antropología filosófica da democracia. In: BRESCIANI, Stella; NAXARA, Márcia (Orgs.). Memória e (res)sentimento. Indagações sobre uma questão sensivel. Campinas: Ed. Unicamp. 2001. p. 388.

53 Ibidem, p. 389. 
a afirmação do nacional não se revela apenas nesses lugares, mas também no tensionamento entre a uniformização e as distinções.

Portanto, a possibilidade de desconstruir o discurso totalizante e mitificador sobre o envolvimento do brasileiro com o futebol é trabalhar esse contraditório. Uma produção historiográfica significativa tem procurado problematizar essa questão, utilizando-se das potencialidades etnográfica e documental, para a compreensão dos agentes envolvidos no sistema futebolístico. Procura-se apreender a fala dos personagens das torcidas organizadas de futebol, ${ }^{54}$ sobre a formação dos jogadores, ${ }^{55}$ sobre a imprensa e a crônica esportiva, ${ }^{56}$ sobre as formas de gerenciamento, ${ }^{57}$ entre outros. E é nesse trajeto crítico que pretendemos inserir a perspectiva teórico-metodológica dos sentimentos na política.

Acompanhando a metodologia sugerida por Pierre Ansart, ${ }^{58}$ algumas questões podem ser colocadas preliminarmente. Entre as condições primeiras encontra-se a crítica às ciências sociais da dicotomia produzida entre objetivo e subjetivo, entre razão e os signos comoventes. E de como têm sido decorrentes desse raciocínio as visões de que as sociedades tradicionais são mais emotivas do que as complexas, de que as classes populares são menos capazes de atitudes racionais (consequentemente, agem mais pela emoção) e de que as manifestações emotivas só podem ser observadas em situações de crise ou de convulsão social. Desse modo, para boa parte da ciência social e política, não interessam as mensagens das emoções, como a paixão. Predomina nesta ciência a visão da paixão como desvio, exceção ou mesmo fanatismo, ou seja, uma patologia psíquica ou social que incapacita o indivíduo de agir politicamente. ${ }^{59}$ Sobre os sentimentos só lhe interessa

54 TOLEDO, Luiz H. de. Torcidas organizadas de futebol. São Paulo: Anpocs/Ed. Associados, 1996. TEIXEIRA. Rosana da Câmara. Os perigos da paixão. Visitando jovens torcidas cariocas. São Paulo: Annablume, 2003. HOLLANDA, 2009, op. cit.

55 DAMO, Arlei S. Do dom à profissão: formação de futebolistas no Brasil e na França. São Paulo: Aderaldo \& Rothschild Ed., ANPOCS, 2007; RIAL, Carmen. Rodar: A circulação de jogadores de futebol brasileiros no exterior. Horizontes Antropológicos, Porto Alegre, ano 14, n. 30, p. 21-65, jul./dez. 2008 .

56 HOLlANDA, 2009, op. cit.; HOLLANDA, Bernardo B. B. de; MELO, Victor A. de (Orgs.). O esporte na imprensa e a imprensa esportiva no Brasil. Rio de janeiro: 7Letras, 2012.

57 RIBEIRO, Luiz Carlos. Reordenamento das ligas de futebol. Crise ou nova ordem? Recorde: Revista de História do Esporte, v. 5, n. 1, junho de 2012. Disponível em: < http://www.sport.ifcs. ufrj.br/recorde/home.asp>. Acesso em: junho de 2012.

58 ANSART, 1983; 2000, op. cit.

59 ANSART, 1983; 2000, op. cit. 
o controle. Referindo-se aos estudos da política, Pierre Ansart coloca a extensão do problema da seguinte maneira:

A dimensão afetiva da vida política, os sentimentos comuns, as paixões coletivas que participam das práticas políticas, constituem um domínio de difícil conhecimento, um desafio, portanto. Como compreender e explicar a intensidade de uma emoção coletiva e suas consequências, a persistência de um apego, a violência de um amor ou de ódios políticos? ${ }^{60}$

Para este autor, "a recusa em enfrentar essas dificuldades tem sido a solução mais comum", na medida em que o racionalismo cientificista eliminou as experiências cotidianas de seu campo de observação, "para somente reter da 'realidade' política aquilo que pode ser traduzido racionalmente", resultando disso o fracasso do conhecimento. ${ }^{61}$

De maneira diversa dos intelectuais de matriz positivista e marxista, Ansart afirma a necessidade de se redescobrir as paixões políticas, pois “é preciso pesquisar como as paixões, as emoções, os sentimentos acompanham e sustentam as práticas políticas particulares e através de quais procedimentos, de quais agentes e com quais consequências". ${ }^{62}$

As estratégias propostas por Ansart para a compreensão histórica da paixão apontam inicialmente para o reconhecimento de "sinais" das emoções e dos sentimentos. Sinais que só podem ser compreendidos em uma perspectiva sociocultural, logo, não oposta à cognição. As emoções, explica o pensador, pertencem ao campo dos "afetos vivos e limitados no tempo". ${ }^{3}$ $\mathrm{O}$ que seria distinto dos sentimentos, pois esses expressam "sistemas socioafetivos menos aparentes e mais duráveis", ${ }^{64}$ tal como o ressentimento por uma injustiça social. Apesar de Prochasson não se preocupar com essa distinção, sua conceituação é próxima:

Emoção encontra seu equivalente no velho sentido da palavra paixão, que designa o conjunto de movimentos afetivos, mais

60 ANSART, 1983, op. cit, p. 7.

61 Idem.

62 Ibidem, p. 8.

63 ANSART, 2000, op. cit., p. 153.

64 Idem. 
ou menos estáveis, engendrados pelo choque de um estado individual com a análise de uma situação. ${ }^{65}$

Para ambos, a estratégia para a compreensão histórica das paixões é percebê-las como expressões (signos) essenciais e práticas significativas dos indivíduos e das sociedades.

A proposta para perceber e analisar essas manifestações é inquirir sobre o passado do sistema socioafetivo, nas suas diversas formas de manifestação: crenças, expressões políticas, seus símbolos de legitimação e de perpetuação, os imaginários construídos, suas continuidades e descontinuidades, os usos dados à carga afetiva. Sem descuidar da relevância do sujeito individual, não perder de vista o caráter coletivo das emoções e, sobretudo, as suas relações intersubjetivas. ${ }^{66}$

É nesse sentido que, para deixar de ser uma expressão vazia, folclórica, a afirmação da paixão do brasileiro pelo futebol precisa ser historicamente desconstruída. Deve-se evitar a tentação de explicar o complexo pelo simples. Sistemas, modelos, teorias são necessários e mesmo impossíveis de serem evitados, pois toda narrativa é produtora de sínteses, mas eles não podem, em nome da clareza, eliminar o contraditório, as alteridades. É uma dialética radical, que exige do historiador o compromisso com a experiência concreta e polissêmica dos indivíduos e das instituições.

A sobreposição das mensagens comoventes com o social e o cultural não pode soterrar as experiências afetivas dos sujeitos históricos. As frases recorrentes - lugares-comuns - de que o futebol "explica o Brasil", que o futebol é "paixão nacional" ou de que "o amor ao clube é incondicional" são afirmações tautológicas e reprodutoras de discursos autocentrados. Por isso, precisam ser demonstrados historicamente. O "fazer-se", para tomarmos o conceito de Thompson.

Nessa direção, a estratégia damatteana de pensar o futebol como "drama social" sem dúvida nos ajuda, desde que não fiquemos engessados nas estruturas sociais e culturais que delimitam esse "drama". É preciso compreender a paixão do brasileiro pelo futebol como um tema polissêmico, tensionando e historicizando os diversos componentes desse sentimento.

65 PROCHASSON, 2005, op. cit., p. 312. Grifos no original.

66 ANSART, 2000, op. cit.; PROCHASSON, op. cit. 
Para explicar a "diáspora esportiva" do futebol - desde a Inglaterra vitoriana - e o processo de "descodificação parcial" que ele sofreu no Brasil, Arlei Damo utiliza-se da expressão "canibalismo simbólico". ${ }^{67}$ Certamente, se referia à tese da antropofagia que os modernistas dos anos 1920 elaboraram para explicar o caráter da nossa brasilidade.

O exemplo é oportuno, pois em 1922, contemporâneo à semana modernista, a recém-criada (1916) Confederação Brasileira de Desportos procurou organizar um campeonato nacional entre os selecionados estaduais, tendo como motivo a comemoração do centenário da independência do Brasil.

Diante da desordem econômica e política que vivia a sociedade brasileira e mundial naquele momento, não é difícil constatar os ressentimentos que as elites locais tinham em relação aos fracassos de justiça e equidade que a República havia prometido, em favor do desmanche das estruturas políticas do antigo regime.

Além das disputas esportivas e políticas entre Rio de Janeiro e São Paulo, pouco se conhece do posicionamento das ligas e clubes dos outros estados em relação aos projetos de nacionalização do futebol. A maioria dos dirigentes dessas localidades estava envolvida em disputas identitárias regionais, tanto políticas quando esportivas, e muito provavelmente o seu olhar para o "nacional" era mais no sentido de afirmação local.

No plano cultural e político dos anos 20 , é possível perceber a diversidade e o embate em torno da chamada questão nacional. Há vários brasis quando nos referimos à boemia carioca de João do Rio e Di Cavalcanti, à antropofagia dos paulistas ou ao "paranismo" dos curitibanos. É evidente o ressentimento político presente, por exemplo, nesse Manifesto Regionalista, ${ }^{68}$ de Recife, em 1926:

A maior injustiça que se poderia fazer a um regionalismo como o nosso seria confundi-lo com separatismo ou com bairrismo. Com anti-internacionalismo, antiuniversalismo ou antinacionalista. Ele é tão contrário a qualquer espécie de separatismo que,

67 DAMO, 2007, op. cit., p. 36.

68 A veracidade desse documento é contestada por alguns críticos culturais. Ver: MARTINS, Wilson. O Manifesto Regionalista que não houve. Jornal da Poesia. 1998. Disponível em: <http://www. jornaldepoesia.jor.br/wilsonmartins033.html>. Acesso em: 21.03.2003. 
mais unionista que o atual e precário unionismo brasileiro, visa à superação do estadualismo, lamentavelmente desenvolvido aqui pela República - este sim, separatista - para substituí-lo por novo e flexível sistema em que as regiões, mais importantes que os Estados, se completem e se integrem ativa e criadoramente numa verdadeira organização nacional. ${ }^{69}$

Era comum, também, o rancor em relação aos projetos nacionalizantes da CBD, nesses anos 20. No citado campeonato interestadual de 1922, a seleção baiana, que havia conquistado um honroso segundo lugar, título dividido com os cariocas, teve a seguinte reportagem na imprensa local, em que se observa o recalque dos baianos por se sentirem desprezados pelos clubes e federações de Rio e São Paulo:

Que ideia poderiam eles fazer de nós, então a de que éramos uns principiantes, apalpando agora o terreno que eles já pisavam firmes e conscientes?

[...] Mas os nossos guardavam em segredo, no escrínio da nossa abençoada modéstia de desprezados nortistas, as reservas do progresso e grandeza de que demos mostras às vistas, que se diriam duvidosas de que fosse verdade o que viam mais de 32.000 pessoas.

[...] Vivemos neste momento a grandeza desse feito e a lição inapreçável que ele representa para nós. Convençamo-nos de que na Bahia há valor, há heroísmo. A Bahia é desprezada porque nós nos encerramos aqui dentro, calados e obstinados a escurecer o que é nosso. Escapamos ao espírito ávido de aplaudir a grandeza do vizinho, a necessidade de levantar bem alto o nosso nome inconfundivelmente em todas as esferas. ${ }^{70}$

Essas citações não apenas revelam disputas e interesses políticos conflitantes - já bastante conhecidos na literatura histórica -, como nos

69 FREYRE, Gilberto. Manifesto regionalista. 7. ed. Recife: FUNDAJ, Ed. Massangana, 1996. p. 47-75. Disponível em: <http://www.ufrgs.br/cdrom/freyre/freyre.pdf > Acesso em: 20.06.2012.

70 SANTOS, Henrique Sena. Nos gramados do Sul: a Bahia e o Torneio do Centenário em 1922. In: SIMPÓSIO NACIONAL DE HISTÓRIA - ANPUH, 26., São Paulo, 2011. Anais... São Paulo, julho de 2011. 
dizem sobre a forma como as tensões são sentidas pelos agentes. A maneira utilizada para marcar a distinção em relação a Rio e São Paulo é carregada de comoções. Uma estratégia que se preocupa mais em afirmar o regional do que se inserir no nacional, mesmo quando este é afirmado. A nação não é negada (não há um discurso separatista), mas afirmada como diversa, não uniforme. A ênfase do discurso não se encontra numa análise racional que poderia considerar a importância política do Rio de Janeiro como capital federal, ou de São Paulo como pujança econômica. O raciocínio é pautado por manifestações subjetivas de ressentimentos, que servem tanto para desqualificar o outro quanto para afirmar positivamente os interesses locais. No exemplo da Bahia, o entusiasmo manifesto em relação ao futebol não é brasileiro, mas baiano. São sentimentos de pertença que se afirmam no rancor da desigualdade (a República, sim, é separatista) e na injustiça de uma Bahia desprezada.

\section{Algumas conclusões}

Os pensadores voltados para a temática dos sentimentos aqui abordados, entre os quais cito especialmente Pierre Ansart, concordam com a dificuldade e as incertezas que o estudo dos sentimentos e das emoções na vida política traz para as Ciências Sociais e Políticas. São ciências de tradição oitocentista, que nasceram engajadas na tarefa civilizadora de fundar e legitimar o Estado e a nação modernos. Desenvolveram-se num círculo ideológico restrito, cuja matriz central era razão e ordem despojadas do social. As paixões, sempre reconhecidas, eram sinais de fraqueza, de incapacidade de ordem, como descreve Prochasson em relação à visão de Tocqueville:

Em Tocqueville, as paixões não desempenham, senão muito excepcionalmente, um papel positivo. Os adjetivos que ele lhes atribui são, muitas vezes, negativos: as paixões são cegas, surdas, imponderadas. Elas revelam a renúncia à vontade. ${ }^{71}$ 
De origem latina (patior), paixão etimologicamente significa sofrer, suportar, ser passivo. A paixão, nesse sentido, tem o significado da perda de si, da perda do autocontrole, da capacidade de discernir, ou seja, de viver em sociedade. Nesse sentido, o mal-estar da civilização se encontra nos fracassos em estabelecer os domínios, em lapidar a matéria bruta das paixões. ${ }^{72}$ Mas, é também pensada como a capacidade que nos faz agir. A paixão faz o homem corajoso, revolucionário, arrebatador, capaz de "uma loucura!". A paixão impulsiona a história.

As manifestações emotivas no futebol são evidentes na prática do pertencimento clubístico, ${ }^{73}$ assim como se exacerbam na violência das torcidas organizadas. São manifestações tanto de controle e sociabilidade quanto de ressentimento e vontade de vingança, como, por exemplo, a injustiça social que gera a vontade de agredir. São práticas que não podem ser lidas como exclusivas do sistema futebolístico. A vontade de vingar, desde a forma mais controlada de fazer justiça, até o uso de formas simbólicas ou físicas de violência, são expressões de uma angústia civilizacional que perpassam todo o tecido social.

$\mathrm{O}$ crescimento da violência no futebol, assim como as ressignificações aos sentidos de pertencimento ao clube ou à seleção nacional, precisam ser estudados de maneira a contemplar as subjetividades das práticas sociais. A tradução binária de racional e emotivo não pode anular a riqueza da relação intensa dessas instâncias.

O que propusemos neste ensaio foi, inicialmente, problematizar a construção do campo de estudo, atentando para as leituras sobre o futebol, que não podem ficar engessadas a categorias imóveis, por mais relevantes que elas tenham sido para a constituição do campo. As bases dos estudos sobre o esporte foram elaboradas a partir do conhecimento crítico engajado em explicar a nação. Um engajamento missionário, como foram quase todos os intérpretes do Estado, da nação e do nacionalismo, no Brasil.

Nesse sentido, procurei esboçar algumas estratégias possíveis para superar essa hegemonia e propor um descolamento das Ciências Sociais e Políticas da missão de pensar o Brasil. É um esforço que deve existir não

72 KEHL, Maria Rita, A psicanálise e o domínio das paixões. In: CARDOSO, Sérgio et al. Os sentidos da paixão. São Paulo: Cia das Letras, 1987. p. 471.

73 DAMO, 2007, op. cit. 
só em relação à ideia de nação, mas também em relação às identidades regionais. Identicamente, é preciso produzir uma narrativa histórica descomprometida com a missão de construir o imaginário regional. Ter, em relação ao discurso local, a mesma postura crítica e não cair na armadilha de reproduzir o recalque de excluído e se arvorar em paladino que lutará contra as injustiças sociais.

A tarefa não é fácil. Mas, com este ensaio, estamos nos comprometendo com a tarefa de construir uma agenda de estudos sobre o esporte no Brasil que, a partir dos trabalhos já existentes, se abra para possibilidades de uma história política da nossa paixão pelo futebol.

Recebido em julho de 2012. Aprovado em agosto de 2012. 